\title{
A STRAIN OF STAPHYLOCOCCUS RESISTANT TO FIVE ANTIBIOTICS
}

\author{
BY \\ KEVIN ANDERSON \\ From the Department of Bacteriology, Guy's Hospital Medical School, London
}

(RECEIVED FOR PUBLICATION OCTOBER 20, 1953)

Since the use of antibiotics in the treatment of staphylococcal infections has become established, the emergence of resistant strains has been frequently reported. The incidence of penicillin resistance has been described by Barber and Rozwadowska-Dowzenko (1948), Barber, Hayhoe, and Whitehead (1949), Rountree and Thomson (1949), and by Cairns and Summers (1950). Organisms resistant to penicillin and streptomycin isolated from two cases of meningitis have also been described (Anderson and Ellis, 1951). While testing the sensitivity of freshly isolated strains of pathogenic bacteria to terramycin and other antibiotics, Ransmeier, Brown, and Davis (1951) found four strains of Staph. pyogenes which were resistant to penicillin, streptomycin, chloramphenicol, aureomycin, and terramycin. Clarke, Dalgleish, and Gillespie (1952) report the appearance and dissemination in hospital of staphylococci showing resistance to these five antibiotics and also to sulphadiazine.

Changes which take place in staphylococci developing resistance in vivo to penicillin have been reported by Spink, Ferris, and Vivino (1944), who showed that such resistance was often accompanied by increased susceptibility to the bactericidal action of whole blood, and possibly to other defence mechanisms. Klimek, Cavallito, and Bailey (1948), studying a strain made resistant to penicillin in vitro, found that at a level of $1 \mathrm{mg}$. per $\mathrm{ml}$. the fermentation reactions of the organism were almost completely suppressed. Pigmentation was first reduced and then completely lost ; haemolysis was retarded and the coagulase reaction was negative in the single test conducted. Bellamy and Klimek (1948) describe variants which were resistant to $1-4 \mathrm{mg}$. of penicillin per $\mathrm{ml}$. and had lost the ability to produce acid from lactose, sucrose, maltose, and mannitol. They would not grow in the presence of $6.5 \%$ sodium chloride nor would they reduce nitrates.
A strain of staphylococcus recently isolated in these laboratories from a cerebral abscess provedo to be resistant to five antibiotics and also to sulpha의 diazine. The organism was so atypical on primary isolation that a detailed study of it was made i an attempt to discover what changes might be associated with multiple resistance to antibioticso The clinical history of the strain and the invest gations made are now considered in detail.

\section{Clinical History}

The patient, J.A.D., a man aged 46 years, was admitted to the Maudsley Hospital, London, of August 12, 1953, with a provisional diagnosis of cerebral abscess. For 24 hours before admission $h \overrightarrow{\vec{E}}$ had been given penicillin, 1 mega unit four-hourl $\mathrm{B}$ and sulphadimidine, 3 g. six-hourly. While if hospital, he received systemic penicillin, 1 mega und six-hourly for five days, and streptomycin $1 \mathrm{~g}$. b. also for five days. Aureomycin was given orally a dosage of $1 \mathrm{~g}$. b.d. for four days and three doses of chloramphenicol to a total of $3 \mathrm{~g}$. were given $\overrightarrow{3}$. eight-hourly intervals just before death on Auguigt 17. Chloramphenicol, $2 \mathrm{mg}$., and $50 \mathrm{mg}$. of streptor mycin were instilled into the left and right ventricles through frontal burr-holes. At necropsy a right temporo-sphenoidal abscess was found. There was ne obvious pathology in any of the systems to accoug for this. Pus from the abscess was taken for bacteriological examination. Gram-stained filn? showed large numbers of Gram-positive cocci, and culture yielded a growth of a staphylococcus. N

\section{Colonial Morphology and Growth Characteristies}

On primary isolation on aerobic horse blog్ agar, the colonies were somewhat smaller then normal, but the general contour and surface tex ture did not present any unusual features. The colonies lacked pigment, and even scraping the growth failed to demonstrate it. Plates kepgt at room temperature for seven days did not show any significant pigment. There was no haemolysis of the surrounding medium. The growth wogs 
viscid and stringy in consistency but emulsified well in saline, and there was no auto-agglutination. Gram-stained films showed a Gram-positive coccus of normal morphology, size, and arrangement.

Growth in nutrient broth produced a uniform turbidity with a stringy deposit which could be dispersed by shaking. Turbidimetric studies showed that the rate of growth in broth was considerably slower than that of the Oxford staphylococcus under similar conditions. The organism grew well on nutrient agar, and in gelatin stab cultures produced fully developed saccate liquefaction in seven days at room temperature. It grew in the presence of $6.5 \%$ sodium chloride, but rather more slowly than a control strain.

\section{Biochemical Reactions}

Five sugars were inoculated and examined at the end of seven days' incubation at $37^{\circ} \mathrm{C}$. The organism produced acid in glucose, lactose, and saccharose but failed to ferment maltose or mannitol. In litmus, milk acid and clot were formed after 48 hours' incubation. The methyl red test and the Voges-Proskauer reaction were both positive. Nitrates were reduced and ammonia was formed. Neither indole nor hydrogen sulphide was produced.

\section{Production of Coagulase}

The organism was first tested on the slide by the method of Cadness-Graves, Williams, Harper, and Miles (1943). Only slight granularity of the emulsion could be produced compared with the massive clumping of a control strain. Different samples of plasma gave identical results. Repeated sub-culture on blood agar resulted in some increase in clumping, but the reaction remained less vigorous than that given by a control organism.

This led to a more detailed investigation of the coagulase-forming properties of the strain and a tube test was set up in the following manner. Samples of citrated human and rabbit plasma were diluted 1 in 5 and 1 in 10 with both nutrient broth and with saline. Tubes containing $1 \mathrm{ml}$. of these plasma dilutions were inoculated with $0.1 \mathrm{ml}$. of an 18-hour culture of the organism. Duplicate tubes were inoculated with a known coagulase producer and a further rack of plasma dilutions acted as a control. All racks were incubated at $37^{\circ} \mathrm{C}$. and negative tubes were left overnight before being finally recorded. The result of this experiment is summarized in Table $\mathbf{I}$.
TABLE I

COAGULASE ACTIVITY OF STRAIN J.A.D. AND POSITIVE CONTROL

\begin{tabular}{|c|c|c|c|c|c|c|c|c|}
\hline & \multicolumn{4}{|c|}{ Rabbit Plasma } & \multicolumn{4}{|c|}{ Human Plasma } \\
\hline & \multicolumn{2}{|c|}{$\begin{array}{l}\text { Dilution } \\
\text { in Broth }\end{array}$} & \multicolumn{2}{|c|}{$\begin{array}{l}\text { Dilution } \\
\text { in Saline }\end{array}$} & \multicolumn{2}{|c|}{$\begin{array}{l}\text { Dilution } \\
\text { in Broth }\end{array}$} & \multicolumn{2}{|c|}{$\begin{array}{l}\text { Dilution } \\
\text { in Saline }\end{array}$} \\
\hline & $1: 5$ & $1: 10$ & $1: 5$ & $1: 10$ & $1: 5$ & $1: 10$ & $1: 5$ & $1: 10$ \\
\hline $\begin{array}{l}\text { Strain } \\
\text { J.A.D. }\end{array}$ & - & - & - & - & - & - & - & - \\
\hline $\begin{array}{l}\text { Positive } \\
\text { control }\end{array}$ & $\begin{array}{c}+ \\
(40 \\
\min .)\end{array}$ & $\begin{array}{c}++ \\
(40 \\
\text { (min.) }\end{array}$ & $\begin{array}{c}+\dot{+} \\
(40 \\
\min .)\end{array}$ & $\begin{array}{c}+ \\
(40 \\
\min .)\end{array}$ & $\begin{array}{c}+ \\
(40 \\
\min .)\end{array}$ & $\begin{array}{c}+ \\
(40 \\
\min .)\end{array}$ & $\begin{array}{c}+ \\
(40 \\
\min .)\end{array}$ & $\begin{array}{c}+ \\
(40 \\
\min .)\end{array}$ \\
\hline $\begin{array}{l}\text { Plasma } \\
\text { controls }\end{array}$ & - & - & - & - & - & - & - & - \\
\hline
\end{tabular}

$+=$ clot formation. The times taken for clot formation are shown in parentheses.

\section{Toxin Production}

The strain was examined for haemolysin production by the plate method described by Elek and Levy (1950a). Repeated tests showed that only the $\delta$ toxin was produced. Further tests were performed using the double diffusion gradient principle (Elek and Levy, 1950b). The strain was found to produce only two antigen-antibody flocculation lines after 48 hours' incubation in an atmosphere of air plus $30 \% \mathrm{CO}_{2}$.

\section{Animal Pathogenicity}

A rabbit was injected intravenously with 0.5 $\mathrm{ml}$. of an 18-hour broth culture. At the end of seven days the animal still appeared well and was sacrificed. Necropsy showed no abscess in any of the internal organs and the spleen was of normal size. Pathogenicity was further assessed using the mouse as a test animal. The intramuscular method of Selbie and Simon (1952) and the intraperitoneal method of Christie, North, and Parkin (1946) were both employed. The former technique, which provides finely graduated readings, showed an increase of only $1 \mathrm{~mm}$. in the diameter of the injected thigh after the first day. Subsequent measurements failed to demonstrate any difference between the control and the test limbs. In the intraperitoneal method of Christie et al., $1 \mathrm{ml}$. of the standard bacterial suspension was injected into three mice. No deaths occurred in the 48 hours following injection.

\section{Antibiotic Sensitivity}

The staphylococcus was first screened for sensitivity by the plate method using compressed antibiotic tablets (Evans Medical Supplies Ltd.). It was evident by this method that the strain was resistant to penicillin, streptomycin, chlorampheni- 


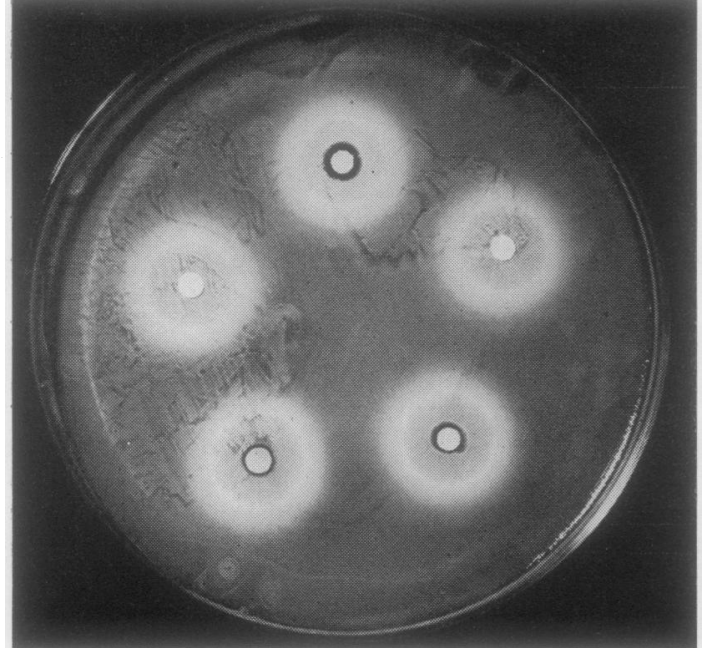

FIG. 1.-Antibiotic spectrum of strain J.A.D. Antibiotics from the top disc, clockwise, are chloramphenicol, penicillin, terramycin, aureomycin, and streptomycin.

col, aureomycin, and terramycin (Fig. 1). Sulphonamide sensitivity tests were performed by the method of Harper and Cawston (1945). Growth occurred in the presence of $10 \mathrm{mg}$. of sulphadiazine per $100 \mathrm{ml}$. of medium. The results of the tube titrations using serial dilutions of antibiotics are seen in Table II.

TABLE II

TUBE TITRATIONS OF ANTIBIOTIC SENSITIVITY OF STRAIN J.A.D.

\begin{tabular}{|c|c|c|}
\hline \multicolumn{2}{|c|}{ Antibiotic } & $\begin{array}{c}\text { Inhibitory Concentration } \\
(\mu \mathrm{g} . / \mathrm{ml} .)\end{array}$ \\
\hline $\begin{array}{l}\text { Penicillin } \\
\text { Streptomycin } \\
\text { Chloramphenicol } \\
\text { Terramycin } \\
\text { Aureomycin }\end{array}$ & $\begin{array}{ll}\ldots & \ldots \\
\cdots & \cdots \\
\ldots & \cdots \\
\ldots & \ldots\end{array}$ & $\begin{array}{r}25 \\
>100 \\
100 \\
50 \\
100\end{array}$ \\
\hline
\end{tabular}

\section{Production of Penicillinase}

To three concentrations of penicillin in nutrient broth $1 \mathrm{ml}$. of a six-hour broth culture of the organism was added. The tubes were incubated with uninoculated duplicates for two hours at $37^{\circ} \mathrm{C}$. This time was chosen since it was felt that penicillinase production might be slower with an atypical strain. Samples from each tube were transferred to Heatley cylinders embedded in a plate inoculated with the Oxford staphylococcus. The result of subsequent incubation is shown in Fig. 2.

The quantitative penicillinase production was kindly estimated by Dr. Patrick Collard using an iodometric method described by Perret (1953), and

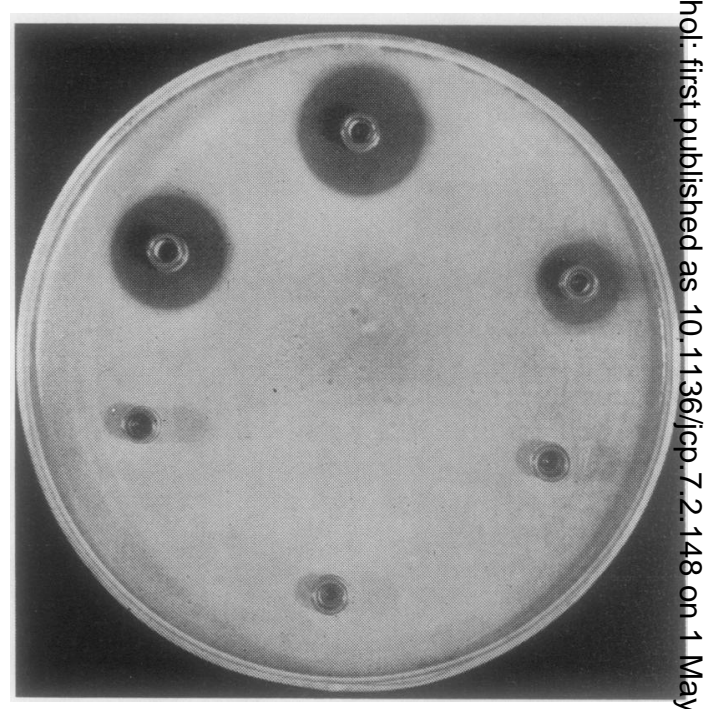

FIG. 2.-Penicillinase production by strain J.A.D. The top three, control cylinders contain 1 unit, 5 units, and 10 units of penicillipo per ml. The lower cylinders contain similar concentrations plus the test organism.

$1 \mathrm{ml}$. of a six-hour broth culture of the organism was found to destroy 640 units of penicillin in one hour.

\section{Phage Type}

Dr. R. E. O. Williams reported that the organ ism was not lysed by any of the standard filtrates in use at that time.

\section{Discussion}

Some of the changes described in strains of staphylococci made highly resistant to penicillig in vitro seem capable of appearing in organisms. clinically resistant to several antibiotics. Of thes changes, the loss of pigment and diminished pro duction of coagulase seem the most likely to give rise to difficulty in identification. In this particus lar case, the slide coagulase test was equivocal and, had the tube test alone been performed, the organ ism might well have been discarded. Fisk (1940) and Duncan and Walker (1942) have drawn atten: tion to the optimum ratio between organism an $\varnothing^{\circ}$ plasma. However, this staphylococcus appeared to produce insufficient extracellular coagulase t? cause clotting when transferred to any of th㐘 plasma dilutions and the slide test gave the only clue to the possible identity of the organism.

The absence of $\alpha$-toxin, the results of an anima inoculation, and the failure to ferment mannitoof (Knott and Blaikley, 1944) may all be taken a\& evidence of reduced pathogenicity and serve te confirm the observations of Spink et al. (1944) thag 
such organisms may be more susceptible to the body defences. It seems unlikely that an organism with these properties could cause a cerebral abscess in man. Elek and Levy (1950a), studying various haemolysin combinations in staphylococci, found that of the strains producing $\delta$ toxin alone, only $2 \%$ were human pathogens, while $39 \%$ were coagulase-positive skin strains. Investigations performed on this strain would appear to confirm the observations of Howard (1954), who found that the number of diffusible antigen-antibody flocculation lines were directly related to the relative virulence of the organism for mice. He also found that strains with a simple haemolysin pattern $(\alpha$ or $\delta)$ gave significantly fewer flocculation lines than those strains with a more complex pattern $(\alpha \delta$ or $\alpha \beta \delta)$.

It is more probable, therefore, that total resistance with its attendant changes developed during the course of treatment, either by adaptation or by the selection of mutants. The patient received all the antibiotics concerned at some time during his illness with the exception of terramycin. However, "cross-resistance" between aureomycin and terramycin is well recognized and has been described by Herrell, Heilman, and Wellman (1950) and by Fusillo and Romansky (1951).

With the increasing use of antibiotics, often in combination, the emergence of staphylococci showing multiple resistance must be expected to occur with greater frequency. The study of this particular strain indicates that the changes described in cocci with artificially induced resistance to penicillin can no longer be regarded merely as phenomena in vitro. The normal characteristics necessary for the identification of Staph. pyogenes fail to apply to such strains and much caution is required in assessing their significance when isolated from pathological material. The apparent loss of pathogenicity in the organism under consideration cannot be regarded with optimism from the clinical point of view, since Clarke et al. (1952) have shown that cross-infection was common with their strains which showed multiple and total resistance to antibiotics.

\section{Summary}

A strain of staphylococcus isolated from a cerebral abscess showed resistance to five antibiotics and sulphadiazine.

Certain metabolic and biochemical changes were demonstrable which have also been described in strains made highly resistant to penicillin in vitro.

Difficulties may be experienced in the identification of such strains isolated from pathological material.

I am indebted to Mr. Murray Falconer, Director, Guy's Maudsley Neuro-Surgical Unit, for permission to publish the details of this case ; also to Mr. Peter Schurr, F.R.C.S., and Mr. B. H. Dawson, F.R.C.S., for access to the clinical notes and for their help in many other ways.

I also wish to thank Dr. R. E. O. Williams, who phage-typed the strain, and the Department of Medical Photography, Guy's Hospital, for Figs. 1 and 2.

\section{REFERENCES}

Anderson, K. F., and Ellis, F. G. (1951). Brit. med. J., 2, 1067. Barber, M., Hayhoe, F. G. J., and Whitehead, J. E. M. (1949). Lancet, 2, 1120.

_ and Rozwadowska-Dowzenko, M. (1948). Ibid., 2, 641.

Bellamy, W. D., and Klimek, J. W. (1948). J. Bact., 55, 153.

Cadness-Graves, B., Williams, R., Harper, G. J., and Miles, A. A. (1943). Lancet, 1, 736.

Cairns, H. J. F., and Summers, G. A. C. (1950). Ibid., 1, 446.

Christie, R., North, E. A., and Parkin, B. J. (1946). Aust. J. exp. Biol. med. Sci., 24, 73.

Clarke, S. K. R., Dalgleish, P. G., and Gillespie, W. A. (1952). Lancet, $1,1132$.

Duncan, J. T., and Walker, J. (1942), J. Hyg. Camb., 42, 474.

Elek, S. D., and Levy, E. (1950a). J. Path. Bact., 62, 541.

- (1950b). Brit. J. exp. Path., 31, 358.

Fisk, A. (1940). Ibid., 21, 311.

Fusillo, M. H., and Romansky, M. J. (1951). Antibiot. and Chemother., $1,107$.

Harper, G. J., and Cawston, W. C. (1945). J. Path. Bact., 57, 59.

Herrell, W. E., Heilman, F. R., and Wellman W. E. (1950). Ann. N.Y. Acad. Sci., 53, 448.

Howard, J. (1954). J. Path. Bact. In the press.

Klimek, J. W., Cavallito, C. J., and Bailey, J. H. (1948). J. Bact., $55,139$.

Knott, F. A., and Blaikley, J. B. (1944). J. Obstet. Gynaec. Brit. Emp., 51, 386.

Perret, J. (1953). Personal communication.

Ransmeier, J. C., Brown, H. E., and Davis, N. (1951). J. Lab. clin. Med., 38, 620 .

Rountree, P. M., and Thomson, E. F. (1949). Lancet, 2, 501.

Selbie, F. R., and Simon, R. D. (1952). Brit. J. exp. Path., 33, 315. Spink, W. W., Ferris, V., and Vivino, J. J. (1944). Proc. Soc. exp. Biol. N.Y., 55, 210. 